\title{
ENTRE MOTOCICLETAS Y FUSILES: LAS ARQUEOLOGÍAS RADICALES ANGLOSAJONA E HISPANA
}

\author{
Randall H. McGuire* \\ Rodrigo Navarrete*
}

La reciente publicación en inglés del diario Mi Primer Gran Viaje (1994) del Ché Chevara en inglés The Motorcycle Diaries (1995) - ha generado un resurgimiento de la icónica figura del Ché dentro de los más variados circuitos del mercado capitalista. En la presentación de la obra se representa al Ché como un James Dean suramericano, quien se embarcó en una travesía hacia el descubrimiento y la aventura. En nuestra opinión esta comparación es altamente problemática ya que confunde la rebelión individual con la revolución, dejando espacio para la definición de espacios políticos reformistas dentro de un programa que precisamente se caracterizó por enfrentarse a estas alternativas.

Las diferencias entre James Dean, el arquetípico rebelde sin causa estadounidense, y el Ché Guevara, el más renombrado revolucionario latinoamericano con una causa de la segunda mitad del siglo $\mathrm{XX}$, son mucho más notorias que sus similitudes. La rebelión de James Dean podría caracterizarse como una trasgresión intimista, individualista, autosuficiente, introspectiva, inefectiva en su proyección a futuro, segura y sin referencia. May por el contrario, la revolución del Ché Guevara conformó parte de un proyecto político social, que implicó un alto nivel de sacrificio personal y grupal, efectiva, peligrosa y significativa. Ambos hombres murieron de manera violenta. James Dean descarriló su aumovil mientras conducía a altas velocidades por una autopista, mientras el Ché dejó la seguridad de la Cuba postrevolucionaria y encontró su muerte acribrillado por las fuerzas militares bolivianas mientras dirigía la lucha revolucionaria en esa nación. Víctimas y símbolos de una misma convul-

(*) Antropologia, Universidade de Binghamton, Binghamton NY, EUA. sionada década, representan precisamente dos extremos de las alternativas frente al cambio.

Consideramos que los arqueólogos que aspiran a desarrollar una aproximación y teorías radicales en arqueología precisamente deben tener presente las diferencias entre rebelión y revolución, las diferencias entre James Dean y el Ché Guevara. De hecho, consideramos que estos dos paradigmáticos íconos culturales están presentes, como modelos, en las formulaciones de teorías radicales tanto en el mundo angloparlante como en el hispanoparlante. Mientras la arqueología radical en los EE.UU. e Inglaterra parece mirar con los desafiantes aires de la rebeldía juvenil de James Dean, la latinoamericana siempre ha tenido como paradigma y referencia el compromiso político de líderes como el Ché Guevara.

\section{Una arqueología efectiva: teoría de la praxis arqueológica}

Como eje general de nuestra visión y acción sobre el mundo, nosotros consideramos que una arqueología radical que aspire a afectar el cambio social tiene que incorporar tres metas en su método: a) Conocer el mundo, c) Criticar el mundo, y c) Actuar sobre el mundo. Conocimiento, crítica y acción conforman así los tres ejes inseparables y indispensables que conforman la praxis de cualquier intelectual que reconozca su función social y su capacidad de transformar la realidad.

Cuando nos referimos a conocer el mundo consideramos en primer lugar que una transformación del mundo depende de su conocimiento concreto. En este sentido, no abogamos por un saber que separe el mundo material de las ideas sino que conforme una unidad dialéctica entre ambos. En segundo lugar consideramos que el conocimien- 
to por el conocimiento en si mismo es autocomplaciente y frecuentemente trivial por lo que aseveramos que el proceso de conocer debe estar estrechamente vinculado con las necesidades sociales e individuales que conforman el contexto del arqueólogo como agente social. En tercer lugar, consideramos que la crítica debe formar parte tanto del proceso cognoscitivo como de su evaluación posterior ya que su ausencia atentaría contra la propia integridad del conocimiento. Si no generamos parámetros epistemológicos, políticos o éticos que guien y evaluen constantemente nuestro acercamiento a la realidad el conocimiento puede desembocar en peligrosas y contraproducentes consecuencias.

Como crítica del mundo, entendemos que todo proceso cognoscitivo crítico involucra tanto la crítica de las condiciones actuales de la realidad proponiendo su modificación, la crítica de otras aproximaciones que sugieren visiones estáticas o idealizadas de dicha realidad, y a su vez, la capacidad autocrítica del propio método. Igualmente, toda aproximación crítica requiere ser respaldada por un conocimiento concreto ya que sólo así es posible evitar debates ilusorios y peligrosas consecuencias no previstas. Finalmente, toda consideración crítica debe estar vinculada a nuestra propuesta de acción sobre el mundo ya que por el contrario, sólo estamos desarrollando aseveraciones nihilistas y que sirven únicamente dentro de su propia esfera de reflexión, como es precisamente el caso de la rebeldía sin causa de James Dean.

De la misma manera, consideramos que como arqueólogos tenemos que abandonar el estéril diálogo interno sobre la arqueología entre arqueólogos y revertir esa reflexión hacia el contexto externo para poder ejercer una acción sobre el mundo. De alguna manera, los complejos contextos de confrontación política, étnica e ideológica de las últimas tres décadas han llevado a algunos científicos sociales a tomar posición en el mundo al reconocer que toda acción si un conocimiento que la respalde es propensa a incurrir en irreversibles errores. Igualmente, la misma acción se ha revertido sobre el conocimiento convirtiéndose en una enriquecedora plataforma para el debate y la crítica, evitando así la propensión a la autoilusión y al totalitarianismo de cualquier conocimiento aislado $o$ absoluto.

Es precisamente en la dialéctica relación entre conocimiento, crítica y acción que la praxis cobra sentido, siempre sobre la base de un contexto concreto. Consideramos que es entonces necesario tener siempre presente la necesidad de una praxis enriquecida por el conocimento, la crítica y la acción aún cuando también es necesario reconocer que sus relaciones y permutaciones son altamente variables de acuerdo con las particularidades contextuales.

\section{Ambos mundos: las arqueologías radicales anglófona e hispanoparlante}

Para comparar el desarrollo de las arqueologías radicales en los mundos anglo e hispano parlantes es necesario en primer lugar reconocer sus variantes internas dentro de cada contexto y el nivel de incidencia de cada una de ellas. Dentro del mundo anglófono, el surgimiento de una arqueología radical parece asociarse a una tácita alianza entre diversas tendencias teóricas en relación a un enemigo común, el procesualismo, aún cuando nunca ha existido un sentido de unidad entre sus variantes. (ver Trigger 1989, McGuire 1992). Así, por ejemplo, tenemos las tendencias postmodernistas y postestructuralistas en Inglaterra y EE.UU. (Hodder 1982, 1986; Shanks y Tilley 1987a, 1987b; Tilley 1990, 1993; Bapty Yates 1990; Preucel 1991; Hodder et al. 1995), y el desarrollo de propuestas feministas fuertemente arraigadas en el contexto norteamericano (Conkey y Gero 1991, Wylie 1992, Wall 1994, Wright 1996, Claassen y Joyce 1997). Los heterogéneos modelos marxistas tanto ingleses como norteamericanos, a pesar de representar la más débil de las tres variantes, son un claro ejemplo de la tendencia a enfrentar un enemigo común dentro de la heterogeneidad (Bender 1989, 1990, 1998; Handsman 1983; Kohl 1985, 1989; Leone 1982; 1988, 1995; McGuire 1992; Patterson 1986,1989b; Paynter 1989; Rowlands 1989; Saitta 1988, 1989, 1997; Trigger 1984; Wurst 1991).

Por su cuenta, en el mundo hispano, el desarrollo y contribución de la arqueología crítica ha sido mucho más homogéneo, especialmente a partir de la contribución a la teoría marxista de la Arqueología Social Latinoamericana (Lorenzo 1976, Patterson 1994, Oyuela-Caycedo 1997). Por el contrario, las tendencias feministas y postmodernistas han presentado un muy bajo perfil con sólo escasos intentos que hasta el momento se han mantenido dentro de los parámetros que lo que ha sido desarrollado en el mundo anglófono (Politis 1992, 1995; Navarrete 1995).

Consideramos que existen diferencias radicales entre el pensamiento postmodemista o postes- 
McGUIRE, R.H.; NAVARRETE, R. Entre motocicletas y fusiles: las arqueologías radicales anglosajona e hispana. Rev. do Museu de Arqueologia e Etnologia, São Paulo, Suplemento 3: 181-199, 1999.

tructuralista y las corrientes marxista y feminista (Kohl 1985, Trigger 1989, McGuire 1992, Navarrete 1995). El pensamiento postprocesualista insiste en términos generales en un relativismo que niega la posibilidad de conmensurabilidad de los discursos arqueológicos, cae en un contextualismo extremo que invalida la posibilidad de encontrar criterios interteóricos de selección y, con la aceptación de la multiplicidad, impiden la selección teórica general. De esta forma, cualquier proposición es válida según su contexto específico de producción teórica y vivencial, y cada individuo o grupo construye un pasado de acuerdo a su propia visión del mundo (Trigger 1989, McGuire 1992, Navarrete 1995). Desde el mismo instante en que se concentra en el mundo del conocimiento como una entidad separada de la realidad concreta, encerrada en su propia lógica de representaciones, ideas y percepciones condicionadas cultural $\mathrm{e}$ individualmente, esta perspectiva ofrece un panorama pesimista, desolador e inutilizador para el futuro de la arqueología, e incapaz de acción política. No existe posibilidad de cambio o transformación del mundo ya que los parámetros de este mundo se diluyen en una infinita, inestable e inaprehensible constelación de visiones irreconciliables.

De esta manera, no es azaroso que este pensamiento se haya desarrollado, recompensado y patrocinado en las universidades líderes a nivel mundial, las cuales evidentemente no sólo son centros de producción del conocimiento sino de alguna manera centros de producción de ideología dominante (Chippindale 1993). Es así como consideramos que la propuesta política del postprocesualismo, aunque inicialmente provocativa y transgresora, mas que revolucionaria - en el sentido de transformación - implica una rebelión reformista. Una vez mas como James Dean, la rebelión termina con el mismo individuo, en este caso con el arqueólogo y su propio discurso.

Por su parte, la tendencia feminista, la cual no ha sido desarrollada en Latinoamérica, ha generado un vibrante y productivo debate crítico fuertemente asociado con la praxis de los arqueólogos como actores sociales. De hecho, como ha sucedido con la Arqueología Social Latinoamericana, la arqueología feminista ha surgido de un interesante encuentro entre movimientos de base y formulaciones teóricas en el contexto anglófono. Es así como no sólo el estudio simbólico sino más importante aún las relaciones de poder y el análisis de clase se han convertido en las herramientas cruciales para entender este asunto, entendiendo la discriminación sexual como un elemento histórico íntimamente asociado con las desigualdades clasistas, racistas o étnicas (Conkey and Gero 1991, Wylie 1992).

Concentrándonos ahora en nuestra perspectiva, el pensamiento marxista supone la existencia de actores sociales en contextos históricamente determinados por relaciones dialécticas económicas y políticas. Colocando al sujeto dentro del contexto social de las relaciones sociales de producción y sus dialécticas acciones y reacciones en relación al medio ambiente, el pensamiento marxista no sólo supone un conocimiento en si mismo sino que supone que este conocimiento es capaz de ejercer acción sobre el mundo. Nuestra posición supone igualmente que el arqueólogo como sujeto social produce un conocimiento condicionado por el contexto sociohistórico de producción, conocimiento que es capaz de revertirse sobre dicha realidad para transformarla - sólo si mantenemos una posición crítica tanto frente a la realidad como frente a nuestro propio conocimiento.

Es interesante reconocer como dicho pensamiento marxista ha frecuentemente anidado en la teoría antropológica europea y norteamericana al menos desde la primera mitad del siglo XX, como es el caso indirecto de la teoría culturalista de Leslie White y sus subsistemas sociales, o como el caso directo del pensamiento evolucionista de Gordon Childe, basado en una revitalización del marxismo decimonónico (Trigger 1989). Sin embargo, es innegable que el desarrollo de una teoría marxista en arqueología se debe en gran medida a la fuerte contribución de Latinoamérica, tanto en el desarrollo del pensamiento radical en general como en el particular caso de la Arqueología Social Latinoamericana (Patterson 1994). La misma presencia del Ché como símbolo global de revolución es testimonio de este fenómeno de praxis revolucionaria genuinamente latinoamericana incidiendo en el resto del mundo.

\section{Haciendo historia: un recuento de ambas arqueologías radicales}

Las arqueologías marxistas en Latinoamérica y los EE.UU. tienen como antecedente común el pensamiento histórico-cultural hasta al menos la década de los cincuenta en ambos contextos. Ya 
McGUIRE, R.H.; NAVARRETE, R. Entre motocicletas y fusiles: las arqueologías radicales anglosajona e hispana. Rev. do Museu de Arqueologia e Etnologia, São Paulo, Suplemento 3: 181-199, 1999.

entrado el siglo XX se visualizaba a los restos del pasado como testimonios de una humanidad que había evolucionado hasta la complejidad del mundo occidental. Durante la segunda y tercera decada de este siglo surge el pensamiento histórico-cultural, fuertemente influenciado por el naturalismo alemán y el culturalismo. $\mathrm{Al}$ asumir la diferencialidad como premisa y evitar los calificativos evolutivos y las cargas valorativas en las interpretaciones culturales, nacieron los pensamientos antropológico y arqueológico actuales, aún cuando el $\mathrm{Su}$ premo Occidental darwinista siempre se mantuvo subyacente a este discurso moderno. El discurso arqueológico normativo se resistió a la elaboración teórica y metodológica pero, en cambio, propició un refinado y exhaustivo desarrollo técnico, consecuente con una ciencia al servicio del progreso de la humanidad, y que debía luchar en contra de la intromisión de cualquier contaminante de tipo político o ético. No obstante, esto no lo mantuvo al margen de las decisiones políticas o sociales (Trigger 1989, Politis 1995).

No obstante, cuando algunas nociones clásicas de la Modernidad y ciertas implicaciones políticas del sistema capitalista entraron en crisis, los arqueólogos sintieron la necesidad de volver a la reflexión. A partir de la década de los sesenta, el desarrollo de nuevas tendencias, que respondían a las necesidades e intenciones del contexto social e individual de su producción, permitió sacar a la arqueología de la crisis de justificación epistemológica en la cual se encontraba. Estas tendencias reflejaban un mundo que necesitaba cambiar la justificación de su presente en base a un nuevo discurso sobre el pasado.

En Latinoamérica, el pensamiento históricocultural continuó siendo el discurso hegemónico durante los sesenta y setenta, enfatizando cada vez más las aproximaciones objetuales y cronológicoestilísticas que distanciaban cada vez el pasado americano de los problemas que confrontaba la actual Latinoamérica (Lumbreras 1974, Sanoja 1983). Como parte del contexto de la crisis global del imperialismo de los EE.UU., el pensamiento marxista en arqueología se desarrolla más temprano en Latinoamérica que en el contexto anglófono (Patterson 1994, Vargas 1995, Politis 1995). La Arqueología Social Latinoamericana estuvo en sus orígenes fuertemente enraizada con un marco científico y político alternativo y antagónico desde los países dependientes latinoamericanos contra el poder hegemónico de las ideologías estadounidenses. Representó evidentemente una ruptura antimperialista en relación a las tendencias dominantes en Europa y los EE.UU., las cuales perdían relevancia epistemológica y social dentro del convulsionado contex to latinoamericano de la época (Lorenzo 1976).

Uno de los elementos cruciales para entender los desarrollos teóricos latinoamericanos es su dialéctica relación con los centros de control políticos e ideológico, tanto en el contexto nacional como transnacional. Las fructíferas trayectorias teóricas de pensamientos latinoamericanos como el indigenismo, el nacionalismo autoctonista y la teoría de la dependencia, por ejemplo, sólo pueden ser entendidas dentro del marco de las tensiones entre los sectores populares y élites de las distintas naciones latinoamericanas y su relaciones con las grandes potencias extranjeras (Vargas 1995, Badillo 1995). Igualmente, el activo papel de los intelectuales en la conformación de movimientos políticos ha sido uno los factores diagnósticos de la teoría latinoamericana desde el siglo XIX, fenómeno que se incrementó con la crisis de los sesenta. Desarrollos teóricos como la Pedagogía del Oprimido (Paulo Freire), la Ciencia Revolucionaria (Fals Borda) y la Investigación Acción precisamente tienen su auge durante esta etapa (Navarrete 1995).

De la misma manera, la Arqueología Social Latinoamericana ha siempre mantenido una contradictoria relación con las teorías arqueológicas europeas y especialmente estadounidenses debido a los ineludibles lazos con la dominación imperialista y la dependencia cultural (Navarrete 1998). Mientras por un lado representa una definitva ruptura epistemológica y política con el paradigma histórico-cultural y su énfasis en la descripción cultorológica, a su vez estuvo lastrada por la presencia de esta tradición en Latinoamérica. En consecuencia, a partir los tardíos sesenta, esta autóctona e innovadora tendencia, cargada de la tradición nacionalista e indigenista revolucionaria de la América Latina del siglo XX, se desarrolla e institucionaliza en base a una base teórico-política común, como lo fue el Grupo Teotihuacán (Lorenzo 1976). Las particularidades de cada país imprimieron sus propias características al cuerpo teórico, lo que conformó un desarrollo heterogéneo siempre ligado a un programa científico y político común. 
McGUIRE, R.H.; NAVARRETE, R. Entre motocicletas y fusiles: las arqueologías radicales anglosajona e hispana. Rev. do Museu de Arqueologia e Etnologia, São Paulo, Suplemento 3: 181-199, 1999.

La vinculación de la arqueología marxista latinoamericana con movimientos políticos concretos está claramente plasmada en el caso cubano. En el sentido general, la Revolución Cubana en 1959 representó un evento paradigmático para el contexto político e ideológico mundial al establecer un nuevo orden en la balanza política global. Para Latinoamérica, Cuba abrió una puerta para la conformación de proyectos políticos revolucionarios en otras naciones y para la incorporación de los sectores intelectuales a estos proyectos. Dentro de la propia Cuba, la implementación de un sistema político socialista implicó consecuentemente una inmersión de la producción científica y humanística en el discurso marxista, especialmente del campo de las ciencias sociales, y por ende de la arqueología (Tabío and Rey 1985). Como consecuencia de este proceso, otros países latinoamericanos como Venezuela, Colombia y Perú revigorizaron sus fuerzas revolucionarias y desarrollaron efectivas fuerzas armas revolucionarias, guerrillas, las cuales tuvieron una fuerte incidencia y respaldo por parte de los sectores intelectuales nacionales. Este es precisamente uno de los principales factores que impulsaron el surgimiento de la arqueología marxista en Perú y Venezuela (Patterson 1994, Oyuela-Caycedo 1997).

Los casos de Chile y Argentina presentan también interesantes elementos en esta discusión. Mientras Argentina ha representado tradicionalmente uno de los principales núcleos de desarrollo intelectual progresista en Latinoamérica, Chile no sólo cumplió con esta condición sino que a su vez se convirtió en la primera nación socialista por elección popular en 1971 en Latinoamérica. Sin embargo, las presiones nacionales e internacionales propiciaron en ambas naciones en los setenta el surgimiento de regímenes dictatoriales, los cuales forzaron un éxodo de numerosos intelectuales hacia naciones democráticas como México, Venezuela, Canadá y Suecia. En el caso mexicano, esto se conjugó con la presencia de una tradición nacionalista e indigenista progresista local (Caso 1958, Bernal 1979). A partir de este productivo encuentro, México se convierte en el comando de acción de la Arqueología Social Latinoamericana en los setenta y primera mitad de los ochenta (McGuire 1992, Navarrete 1998).

En el contexto anglófono, especialmente en EE.UU., la arqueología marxista se desarrolla más tardíamente. A partir de la década de los setenta, la credibilidad en las bondades del sistema de los
EE.UU. comienza a resquebrarjarse. Las desastrosas consecuencias sociales de la guerra de Vietnam, las consecuencias políticas del caso Watergate, las crisis financieras y económicas internas y la perdida de control imperialista, revirtieron no sólo en el discurso público sino también en las ciencias. En el campo de la arqueología, la optimista y tecnocrática Nueva Arqueología comienza a presenciar su propia destrucción desde lo interno. Autores formados bajo esta tradición comienzan a confrontar sus postulados básicos, su vehemente creencia en el método positivista lógico y su ciega fe en la alta tecnología y en la teoría de sistemas, postulando una visión crítica que recogía elementos de tendencias subordinadas (Trigger 1986, Trigger 1989, McGuire 1992).

Es así como el surgimiento del pensamiento marxista en el mundo anglófono, a diferencia que en latinoamericano, está directamente con una reacción al neopositivismo. En algunos significativos pero escasos autores se inicia un replanteamiento de los postulados marxistas en el pensamiento arqueológico a partir de los setenta, tales como Bruce Trigger (1978), Thomas Patterson (1986), Philip Kohl (1981) y Tony Gilman (1984). Un elemento interesante en este surgimiento es que la mayoría de los autores no habían sido formados formalmente en la teoría marxista, como de hecho sucede por tradición en Latinoamérica, sino que por el contrario, fueron autodidactas en relación a un marco teórico-político que aún continuaba siendo ideológicamente adverso al contexto político y fuertemente reprimido o rechazado en múltiples contextos académicos y políticos. Esta tendencia se aglutina posteriormente en los ochenta en torno a las propuestas postestructuralistas.

Este origen diferencial permitió que en muchas ocasiones las tendencias intelectuales características de este pensamiento anglófono incluso parezcan estar enfrentadas a las de la Arqueología Social Latinoamericana, empezando por el fuertemente énfasis antiprogramático y autodidacta de su propuesta. La presencia del pensamiento relacional, el cual supone que las relaciones humanas son la razón y causa de la existencia de fenómenos sociales dialécticos, la fuerte impronta humanista en sus interpretaciones, el foco en la función interpretativa del método materialista dialéctico, son precisamente elementos que lo diferencian del carácter más cientificista, objetivista y substantivista de la versión latinoamericana (McGuire 1992). 
McGUIRE, R.H.; NAVARRETE, R. Entre motocicletas y fusiles: las arqueologías radicales anglosajona e hispana. Rev. do Museu de Arqueologia e Etnologia, São Paulo, Suplemento 3: 181-199, 1999.

\section{Dos visiones de mundo: diferencias en los pensamientos radicales}

Es evidente que las diferencias entre el desarrollo del pensamiento radical en los contextos latinoamericano y estadounidense están asociados con su posición dentro del contexto global. En primer lugar, las tensiones entre centro y periferia conforman un panorama altamente diferencial y antagónico entre ambos casos. La disponibilidad financiera, tanto para el caso de la nación entera como para la arqueología, representa un primer factor limitante o estimulante del desarrollo arqueológico. Mientras en el contexto anglófono las investigaciones arqueológicas poseen un amplio abánico de posibilidades de financiamiento e instituciones de apoyo tanto gubernamentales como privadas, en Latinoamérica las investigaciones arqueológicas están directa o indirectamente financiadas por el Estado, como sucede en términos generales con una gran parte de la cultura latinoamericana (Gándara 1992, Patterson 1994, Oyuela-Caycedo 1997). Sin embargo, este fenómeno produce comportamientos altamente contradictorios en ambos contextos. Mientras en el mundo anglófono la relativa independencia podría permitir cierta libertad de ideas - aún cuando la empresa privada y el Estado continúan dirigiendo los lineamientos -, la abundancia general de recursos permite también una actitud acrítica. En el caso latinoamericano, los resquicios operativos del sistema estatal permiten que la crítica se genere frecuentemente a partir de sus propios aparatos reguladores o académicos; es así como frecuentemente las universidades y centros de investigación, a pesar de depender económicamente del Estado, se convierten en los vértices del pensamiento contestatario (Vargas 1990, Vargas y Sanoja 1993).

Por otro lado, mientras el desarrollo del pensamiento crítico en el contexto anglófono se desarrolla dentro de un contexto imperialista, la de Latinoamérica lo hace dentro de una ideología nacionalista, por lo que sus funciones sociales apuntan hacia distintas metas. Según Trigger (1984) mientras que las propuestas de una arqueología nacionalista apuntan hacia la resolución de problemas políticos e ideológicos propios mediante la definición de problemas y enfoques generados en el mismo contexto que produjo el conocimiento, como sucede con la Arqueología Social Latinoamericana, en los intentos imperialistas el foco está en la apli- cación de metodologías de carácter general o universal sin considerar como las condiciones particulares del contexto nacional o regional podrían incidir en la interpretación del fenómeno. Como es notorio en el caso anglófono son escasos los intentos por desarrollar una teoría marxista que esté comprometida no sólo epistemológica sino políticamente con su objeto de estudio. El proyecto en Annapolis sobre la cultura afroamericana en el contexto de la esclavitud colonial norteamericana y su la concientización de los sectores afroamericanos estadounidenses - el cual discutiremos más adelante - representa una excepción (Leone, Potter y Shackel 1987, Leone 1995).

En consecuencia, como en cualquier relación de dominación imperialista, existen relaciones de dependencia de la periferia con respecto al centro que no sólo se expresan en la explotación económica o en la dominación política sino también en la dependencia ideológica. De hecho, esta es otra de las características que definen una arqueología imperialista: la capacidad de difundir e imponer el discurso hegemónico con el fin de uniformar la ideología imperial (Trigger 1984). Es así como es lógico que exista una mayor penetración de las tendencias teóricas anglófonas en el contexto latinoamericano que a la inversa. Es por esto que precisamente el desarrollo de la Arqueología Social Latinoamericana, como rechazo hacia la escuela histórico cultural, no representa sólo un enfrentamiento a un cuerpo epistemológico sino a una imposición ideológica, mientras que en el contexto norteamericano el enfrentamiento dificílmente pudo trascender por su propio peso hacia las arenas de la acción política. Sin embargo, como antes remarcamos, la presencia del pensamiento hegemónico en el caso latinoamericano juega un papel más contradictorio que en el contexto anglófono ya que la mayoría de los arqueólogos contestatarios no sólo fueron formados bajo la hegemonía imperialista sino que incluso acudieron a sus centros de entrenamiento - universidades norteamericanas - lo que implica un dual juego de confrontación política.

Los arqueólogos norteamericanos viven en el estómago de la bestia, y así producen y reproducen la crítica desde el propio centro de dominación política y a partir de la misma fuente de dominación ideológica, por lo que la crítica está mediada por la interioridad al fenómeno. En el caso de los arqueólogos latinoamericanos la situación es mucho más complicada: muchos se han alimentando de 
McGUIRE, R.H.; NAVARRETE, R. Entre motocicletas y fusiles: las arqueologías radicales anglosajona e hispana. Rev. do Museu de Arqueologia e Etnologia, São Paulo, Suplemento 3: 181-199, 1999.

sus exhalaciones e incluso algunos han habitado en sus intestinos. En consecuencia, paradójicamente algunos de los desarrollos críticos en el contexto latinoamericano podrían ser genuinas expresiones de necesidades locales mientras otros podrían ser sólo una reproducción de los intentos críticos en el discurso hegemónico central. Es así como la condición crítica y la capacidad para la acción en la periferia representa una mayor flexibilidad por la situación de exterioridad frente al centro pero a la vez una inmersión mucho más forsoza dentro de sus parámetros hegemónicos. En otras palabras, es posible percibir a la bestia mejor desde afuera pero siempre formando parte de su nido.

Un factor crucial para diferenciar las arqueologías críticas en ambos contextos es el papel de los intelectuales en la sociedad. Como ya hemos recalcado anteriormente, uno de los elementos que caracteriza a la cultura intelectual latinoamericana es su altísimo nivel de compromiso con la praxis política de la sociedad. Comenzando con las propuestas más conservadoras como el indígenismo estatal en México (Caso 1958, Bernal 1979, Ochoa 1989, Gándara 1992) o Perú (Maríategui 1973, Valcarcel 1981) desde inicios de este siglo, hasta los más contestarias propuestas como las que hemos tratado previamente, el intelectual, incluso aquel que se siempre más cercano a la pulcritud de las ciencias duras, está propenso a actuar directa o indirectamente en el contexto social. De esta manera, las élites políticas e intelectuales coinciden frecuentemente en América Latina, lo que lleva a los científicos o a revertir el conocimiento producido hacia la sociedad, o al menos a reconocer su compromiso político como élite rectora. Mientras en el caso previo los intelectuales como actores sociales son políticamente activos, en el caso de la cultura anglófona su pasividad es resaltante.

En general, los intelectuales norteamericanos e ingleses son consideradas como un sector de las élites nacionales restringida al campo de la producción del saber puro o, en el mejor de los casos, de un conocimiento tecnológicamente aplicable. Por esta razón, el científico en este contexto reside en la impoluta torre de marfil que la superespecialización del trabajo en esta sociedad le ha concedido y de alguna manera su participación en el campo público de la política está restringida. Incluso, en algunos su participación política es abiertamente coartada debido a la concepción ideológica de que la intersección entre discurso científico y político es comprometedora y corrompe la ansiada objetividad del discurso científico.

Esta diferenciación no sólo incide en la acción de los científicos e intellectuales como actores sociales sino también en el papel de las instituciones que los respaldan, especialmente las universidades y centros de investigación (Vargas y Sanoja 1993). Un concepto crucial para las universidades latinoamericanas es el de autonomía, condición jurídica ganada a partir de las acaloradas luchas de las estudiantes de Córdoba (Argentina) en 1917 y defendida consecuentemente en el resto de las universidades latinoamericanas a lo largo del siglo. Según esta visión, aún cuando el Estado sustenta financieramente las universidades, su integridad física, intelectual, política o moral sólo depende de su comunidad y de sus dirigentes internos. Cualquier afrenta contra esta autonomía sería considerada como una violación contra los fundamentos de la libertad constitucional. De esta manera ninguna institución ejecutiva, legislativa o judicial estatal, ni mucho menos sus aparatos represivos pueden atentar contra la libertad universitaria. Por esto las universidades latinoamericanas no sólo se han convertido en símbolos de libertad intelectual y contextos de libre debate político, sino que incluso se han convertido en refugio de tendencias o personalidades políticas rechazadas o reprimidas por el Estado.

Por el contrario, las universidades norteamericanas no son autónomas y sus decisiones administrativas no sólo depeden directamente del Gobierno local sino de las necesidades del mercado capitalista. Con esta comparación no queremos hacer creer que la autonomía universitaria latinoamericana es absoluta e inviolable; muy por el contrario, existen claras evidencias de la intromisión del contexto político y económico nacional y global en su conformación y transformación. Pero en el contexto anglófono está relación forma parte del sistema. De esta manera, las universidades y centros de investigación funcionan según las reglas del mercado y según las regulaciones estatales y no de acuerdo a las decisiones internas. Claramente estamos observando dos tipos de instituciones distintas: mientras en América Latina la comunidad universitaria es capaz de disentir respecto al Estado - aún cuando es frecuentemente reprimida en la expresión de su disersión - en el caso anglófono la universidad es parte del aparato institucional que legitima las necesidades estatales o capitalistas.

Otro problema fundamental es la naturaleza de las organizaciones políticas y del papel de los parti- 
McGUIRE. R.H.: NAVARRETE. R. Entre motocicletas y fusiles: las arqueologías radicales anglosajona e hispana. Rev. do Museu de Arqueologia e Etnologia. São Paulo, Suplemento 3: 181-199. 1999.

dos políticos en la opinión pública nacional. En el caso de Latinoamérica, los partidos políticos se han convertido en instituciones altamente imbricadas no sólo con el Estado Nacional sino también con la conformación de proyectos alternativos. De hecho, la acción pública en América Latina ha estado en gran medida mediada históricamente por el nivel de participación de los partidos políticos en las decisiones nacionales y por el nivel de conexión de éstos con el Estado y las potencias extranjeras (Coronil 1997). De esta manera, así como los partidos de derecha populistas han conformado una clara simbiosis con el Estado, alimentándose y alimentándolo a su vez, los partidos de izquierda latinoamericanos han representado históricamente la contraposición a los proyectos estatales y a la penetración imperialista, desarrollando estrategias de lucha abierta incluso armadas.

En la década de los sesenta y gran parte de los setenta esto se concretó en la formación de fuerzas guerrilleras que servían como el brazo armado de los partidos de izquierda. Esto se conjugó con el hecho de que los sectores intelectuales no sólo se solidarizaron con estos movimientos revolucionarios sino que participaron activamente de su estrategia conformando centros tácticos urbanos para servir de puentes entre los sectores clandestinos y los sectores oficiales de la izquierda, y a su vez con la opinión pública nacional. Un importante factor institucional dentro de este panorama es el rol de los sindicatos en la política nacional, tanto de aquéllos que se plegaron a las necesidades del Estado Nacional como de aquéllos, que fieles a la condición de clase de sus integrantes, conformaron una base de acción para la lucha revolucionaria conjuntamente con los partidos, la guerrilla y los sectores intelectuales. En un contexto intelectual y político como éste la discusión sobre la condición y la conciencia de clase del actor social es mas que inevitable, imprescindible. Mas aún si nos encontramos frente a una sociedad que actualmente sufre de la manera más descarnada y evidente las consecuencias sociales y políticas del neoliberalismo (McGuire 1992, Navarrete 1998).

En los países anglófonos, y especialmente en los EE.UU., el papel de los partidos políticos es bastante más tenue y está matizado más abiertamente por el manejo de la opinión pública por parte de los grandes sectores de poder económico global. A diferencia de los procesos latinoamericanos, como consecuencia de la Guerra Fría los partidos políticos de izquierda se diluyeron y los sindicatos colapsaron. lo que llevó a una despolitización de la opinión pú- blica y una desensibilización de las clases trabajadoras en relación su condición de clase. Es así como frente a una casi absolutista ideología de democracia y de igualdad económica y política por parte del Estado, las políticas radicales son ignoradas o rechazadas y el problema de la condición de clase de los sectores sociales queda relegada tras las discusiones culturales o raciales. Frente a un panorama sociopolítico donde las confrontaciones clasistas son veladas ideológicamente. los intelectuales han generado una aproximación mucho más sutí a las estrategías de cambio, enfocándose precisamente en el análisis de la poderosa ideología que enmascara las desigualdades (Trigger 1989, McGuire 1992).

Gramsci (1971) planteó que existen al menos dos estrategias para enfrentar el orden sociopolítico existente. Uno de ellos, la guerra de movimientos, implica un enfrentamiento abierto, desde las alternativas partidistas hasta las armadas, para lograr el proyecto revolucionario. El otro, la guerra de posiciones, se asocia con una estrategia más pasiva en contra de aquellos gobiernos más eficientemente legitimados y que se inicia a partir de los procesos culturales y la concientización de clase de los sectores oprimidos. De alguna manera, esta diferenciación nos puede servir como esquema para comparar los casos en cuestión: mientras en Latinoamérica la estrategia de la Arqueología Social Latinoamericana fue altamente abierta y comprometida con los procesos revolucionarios, aún cuando desarrolló una aguda crítica a las ideologías legitimadoras, en el caso de las naciones anglófonas la crítica se inició lenta y pasivamente en relación a los procesos ideológicos, para luego tímidamente acercarse los problemas políticos y prácticos asociados. Es así como mientras desde el Manifiesto de Teotihuacán (1976) la arqueología marxista latinoamericana está utilizando el materialismo histórico como herramienta para entender tanto el pasado como para transformar la sociedad presente, en el pensamiento inglés, estadounidense y canadiense la discusión se centró en los problemas teóricos y en la aplicación de este marco teórico al pasado, como ajeno al presente.

\section{Entre arqueologías: comparación de las arqueologías radicales}

Como consecuencia del panorama político e ideológico referido previamente, las arqueologías radicales de estos contextos difieren ampliamente 
McGUIRE, R.H.; NAVARRETE, R. Entre motocicletas y fusiles: las arqueologías radicales anglosajona e hispana. Rev. do Museu de Arqueologia e Etnologia, São Paulo, Suplemento 3: 181-199, 1999.

también en sus tradiciones de pensamiento y mecanismos organizativos. La Arqueología Social Latinoamericana conformó desde sus incios un grupo de pensamiento coherente y fuertemente integrado en base a la visión gremial, o incluso partidista, que su inclinación teórico-político le imprimía. De alguna manera, los grupos como de Teotihuacán o Oaxtepec no eran exclusivamente grupos de discusión teórica o académica, sino, más importante aún, centros de elaboración de programas para la praxis política y funcionaban de alguna manera como bloques de pensamiento dentro de los cuales las élites intelectuales elaboraban, discutían y criticaban directrices para la acción. Si consideramos, por ejemplo, el Manifiesto de Teotihuacán (1976) notamos que la discusión arqueológica cobra relevancia sólo dentro del contexto de la acción política propuesta ya que el conocimiento del pasado es considerado la base crítica necesaria para la transformación del presente (Patterson 1994, Navarrete 1998).

A su vez, esta visión propició una comprensión programática de la labor del arqueólogo tanto en el campo de la propia actividad arqueológica como de la incorporación de este conocimiento a la praxis política. En textos como La arqueología como ciencia social (Lumbreras 1974), Arqueología y Materialismo Histórico (Bate 1977) o Arqueología y Sociedad (Montané 1980) el refinado énfasis metodológico está siempre asociado directa o indirectamente con la necesidad de generar un programa científico capaz de ofrecer una visión "objetiva" de la realidad pretérita y vincularla con las condicione actuales. En consecuencia, la tendencia a unificarse en base un proyecto común homogeneizó la perspectiva general, aún cuando es posible reconocer variantes internas asociadas tanto con las especificidades de los contextos nacionales como con las particularidades de las experiencias teóricas y polítcas de los actores sociales (Navarrete 1998).

El pensamiento marxista en la arqueología anglófona es, en contraposición, mucho más difuso pero a la vez más variado que el caso anterior. Como ya referimos, en gran medida los arqueólogos marxistas en este contexto carecieron de una educación formal en la teoría marxista y frecuentemente fueron autodidactas en su acercamiento a este marco, lo que se aúna al hecho de que sus propios contextos nacionales no propiciaron - e incluso sancionaron - las discusiones marxistas tanto en el campo de la opinión pública como en el mun- do académico (Trigger 1989, McGuire 1992). Igualmente, la carencia de un sentido gremial o partidista, propiciada por la desmobilización de los sectores intelectuales y la despolitización de las universidades, no fomentó el acercamiento, la solidaridad o la unificación sino más bien el aislamiento intelectual y la falta de un programa político común. Es así como la variabilidad está en gran medida determinada por un acercamiento personal a la literatura marxista, lo que ha permitido la presencia de numerosas variantes de acuerdo a los intereses, disponibilidad y tradiciones intelectuales de cada uno de los arqueólogos marxistas angloparlantes. Como consecuencia se ha generado un variado abanico de posibilidades favorecidas por las potencialidades de la teoría marxista: desde propuestas altamente asociadas con el materialismo clásico de la Segunda Internacional (Kohl 1985, 1989; Patterson 1986, 1989b; Trigger 1984), pasando por perspectivas arraigadas en el marxismo estructuralista (Bender 1989, 1990, 1998; Rowlands 1989, Saitta $1988,1989,1997)$, las que prefieren una posición crítica cercana a la Escuela de Frankfurt (Handsman 1983; Leone 1982, 1988, 1995), hasta aquellas más cercanas a lo que se ha denominado Marxismo Hegeliano (McGuire 1992, Paynter 1989, Wurst 1991).

La Arqueología Social Latinoamericana se concentró en un altísimo refinamiento metodológico y en la elaboración de sistemas categoriales y conceptuales que permitieran una comprensión científica del pasado a través del record arqueológico. Los aportes de obras como Antiguas formaciones y modos de producción venezolanos ( $\mathrm{Sa}$ noja y Vargas 1992) y La Arqueología como ciencia social (Lumbreras 1976), Arqueología, ciencia y sociedad (Vargas 1990) parten precisamente de la convicción cientificista de que la transformación de las condiciones presentes depende de un verdadero conocimiento del pasado y de los procesos históricos generales. Consideramos que este énfasis en el conocimiento del mundo podría asociarse nuevamente con la estrategia gramsciana de guerra de movimiento en el sentido de que para desarrollar una acción sobre el mundo antes es necesario establecer un plan sobre bases concretas y objetivas.

Por su parte, la tendencia anglófona ha enfatizado el sentido autorreflexivo de la teoría marxista, es decir, su condición de marco de referencia para la crítica tanto de la disciplina como del cono- 
McGUIRE, R.H.; NAVARRETE, R. Entre motocicletas y fusiles: las arqueologías radicales anglosajona e hispana. Rev. do Museu de Arqueologia e Etnologia, São Paulo, Suplemento 3: 181-199, 1999.

cimiento producido y de su contexto de producción. La idea en este contexto más que la de generar un conocimiento más objetivo o científico del pasado es la de propiciar un marco para crear conciencia sobre las distorsiones y manipulaciones del discurso histórico en el presente. En este sentido, podríamos caracterizarla como una estrategia de guerra de posiciones en la que la concientización se desarrolla a partir de la crítica de los marcos culturales hegemónicos (ver Leone, Potter y Shackel 1987).

Desde su propia teoría sustantiva, la Arqueología Social Latinoamericana tendió a un alto énfasis pragmático y programático en la praxis. Enraizado en una comprensión de la teoría marxista cercana a las visiones clásicas del materialismo histórico, esta escuela de pensamiento otorga primacia a las condiciones materiales de existencia sobre la conciencia social a la vez que enfatiza las relaciones técnicas y sociales de producción como elementos determinantes en la conformación y cambio social (Lumbreras 1974, Vargas 1990). De esta manera, la acción del hombre sobre la naturaleza y sobre los otros hombres es la base del cambio en cualquier proceso y momento históricos. Si vinculamos la teoría sobre el pasado con la comprensión del presente, como la tradición nacionalista e indigenista progresista lo ha hecho en América Latina, podemos suponer que la desigualdad de clases y la dominación imperialista actuales están relacionadas con ese pasado. Más aún, para esta teoría, así como los individuos cambiaron las condiciones en el pasado nosotros tenemos el compromiso en la sociedad presente de hacer lo mismo (Vargas 1990). Es así como la Arqueología Social Latinoamericana se vincula claramante con la noción de guerra de movimiento, en principio porque además surgió históricamente también vinculada a estructuras y creencias partidistas. Debemos recordar que el período de conformación de esta escuela de pensamiento coincide precisamente con la etapa de radicalización política de los intelectuales y centros académicos latinoamericanos.

Por el contrario, la posición anglófona ha sido históricamente más contemplativa. Su énfasis en las discusiones ideológicas en la teoría marxista está fuertemente relacionada con el papel del intelectual en este contexto y a su vez con las singularidades del desarrollo de la teoría marxista en Inglaterra y los EE.UU. El aislamiento de los intelectuales, la censura a la teoría marxista durante la
Guerra Fría, la existencia de un contexto sociocultural totalmente adverso a la discusión de clases, la debilidad de los partidos políticos de oposición $\mathrm{y}$, más importante aún, el hecho de estar precisamente en el centro imperial, generó que sólo con la crisis política de finales de los sesenta y principios de los setenta los intelectuales se acercaran a la teoría marxista como herramienta crítica. Pero más que con una posición activista directamente enfrentada a los aparatos políticos hegemónicos esta teoría desarrolló una estrategia dentro del espíritu de la guerra de posiciones, es decir, partiendo del abordaje de los problemas ideológicos del sistema. En consecuencia, la arqueología marxista anglófona ha desembocado en una posición autoreflexiva basada en el desarrollo de profundas críticas de la perspectiva arqueológica. Igualmente, se focaliza fuertemente en la critica del modo como el discurso arqueológico está profundamente imbricado con los procesos ideológicos y culturales de su contexto de producción (ver Yoffe y Sherratt 1993).

Esta crítica ha generado una revaluación de la manera como ha sido visto el pasado y en consecuencia de las teorías y métodos utilizadas. Esta aproximación ha permitido un productivo diálogo interno y una sinceración del discurso arqueológico y su función social, así como de los arqueólogos como agentes sociales. Sin embargo, también es verdad que su encierro dentro de los propios parámetros de la discusión académica ha propiciado una riesgosa actitud nihilista que continua manteniendo a los arqueólogos aislados de la acción discutiendo cada vez más complejas y elitistas reflexiones, dentro de la más segura e inefectiva torre de marfil del mundo intelectual.

Como parte de este mismo contraste, mientras en América Latina la Arqueología Social se involucró activamente en debates intelectuales de escala general, tanto a nivel nacional como continental e incluso global, en EE.UU. la discusión sólo se ha mantenido dentro del propio circuito y la propia audiencia arqueológica. Evidentemente, otra vez nos encontramos con el problema del papel del intelectual.

\section{Luchas compartidas: elementos y problemas comunes de ambas arqueologías}

A pesar de todas las dramáticas diferencias entre ambas propuestas, ambas arqueologías radicales 
McGUIRE, R.H.; NAVARRETE, R. Entre motocicletas y fusiles: las arqueologías radicales anglosajona e hispana. Rev. do Museu de Arqueologia e Etnologia, São Paulo, Suplemento 3: 181-199, 1999.

mantienen ciertos elementos en común. En principio, ambas han tenido un relativo éxito como alternativas críticas, aún cuando el radio de acción y los alcances de cada una han estado condicionados por los contextos anteriormente examinados. En Latinoamérica la intención permanente ha sido la de trascender el ámbito de la discusión académica, por lo que la Arqueología Social Latinoamericana no sólo se ha concentrado en la crítica interna del discurso arqueológico hegemónico sino que se ha volcado hacia la crítica social y política y ha mantenido conecciones con los sectores activos en la política nacional (Vargas y Sanoja 1993). Sin embargo, si evaluamos cuál ha sido su capacidad de acción real es probable que encontremos que aún así es difícil deslatrarse del mundo de las discusiones intelectuales. Por su cuenta, el pensamiento norteamericano en general se ha encerrado precisamente dentro de este circuito intelectual y mientras su capacidad de crítica interna ha sido fructífera, ha estado frecuentemente imposibilitado de trascender a la crítica externa y a la acción social. De esta manera, el éxito de ambas tendencias como perspectivas críticas ha sido a su vez crucial pero limitado.

En términos del conocimiento producido, es evidente que ambas tendencias han generado novedosas propuestas teóricas y metodológicas que se han incorporado a las discusión y crítica de la teoría marxista y, más importante aún, han expandido en gran medida el panorama histórico sobre el cual se ha aplicado tradicionalmente el pensamiento materialista histórico. La teoría marxista ha estado tradicionalmente vinculada con el análisis de las sociedades capitalistas y la inmersión de otros modos de producción dentro de su esquema, aún cuando desde los mismos manuscritos de Marx era posible reconocer su aplicación como teoría general de la historia. Al ser aplicada a sociedades cronológicamente muy anteriores a la sociedad capitalista y al intentar analizar estructuras y mecanismos de organización completamente distintos a la organización capitalista, la arqueología marxista no sólo ha expandido el campo cronológico sino interpretativo del marxismo. El problema aquí es que precisamente debido a que se requiere la constante elaboración y reevaluación de sistemas teóricos y críticos, la arqueología marxista ha tendido a desbalancear su peso hacia un aspecto de la discusión dejando escaso espacio para el desarrollo de otros que lo complementan.
Por ejemplo, en el caso latinoamericano, debido al carácter programático de la propuesta, la tendencia ha sido desarrollar rigurosos y sofisticados sistemas categoriales y conceptuales capaces de dar sentido a las condiciones de sociedades pretéritas no-capitalistas dentro del marco del una teoría marxista, como es el caso del Sistema Tricategorial desarrollado por el Grupo Oaxtepec (Vargas 1990). Estos acercamientos han sido profundamente enriquecedores pero a su vez han marcado la tendencia hacia un excesivo énfasis en las definiciones y en la búsqueda de un modelo general que en ocasiones han medrado las iniciativas de crítica y de aplicación en los estudios particulares. De hecho, los acercamientos particulares han sido escasos, entre los que podemos contar los de Sanoja y Vargas a los sitios de Orinoco y la costa oriental venezolana (Sanoja 1979, Vargas 1979, 1981), los de Lumbreras en el sitio de Chavín de Huantar (Lumbreras 1989). Por el contrario, los proyectos generalizadores que abordan el desarrollo de las formaciones sociales de manera nacional o continental son sumamente abundantes (Lumbreras 1976, 1983; Bate 1983, 1986, 1988, 1990; Sanoja 1983, 1994; Vargas 1990; Sanoja y Vargas 1992).

Por el contrario, en el caso anglófono la falta de conexión entre los arqueólogos marxistas y su énfasis en los aspectos críticos de la teoría marxista ha generado una casi total ausencia de interés por la revisión del método materialista histórico como modelo unificador, lo que conlleva frecuentemente a la repetición de tradicionales modelos cognoscitivos o a la definición unilateral de nuevos marcos conceptuales según las necesidades específicas del proyecto investigativo.

A pesar de las diferencias entre ambos contextos también consideramos que existen problemas comunes entre los dos desarrollos. Ambos comparten el hecho de que desde su metodología se hace necesaria una intervención en la realidad social que genera el conocimiento, lo cual la convierte en instrumentos intelectuales - o científicos - altamente poderosos para la acción social. Sin embargo, en ese mismo fenómeno reside su debilidad ya que el salto de la teoría a la praxis social requiere de un esfuerzo político y ético de mayor envergadura que la discusión intelectual. Uno de los problemas claves es la relación entre el énfasis particularista de la discusión arqueológica, frecuentemente focalizado en microhistorias y discursos 
McGUIRE, R.H.; NAVARRETE, R. Entre motocicletas y fusiles: las arqueologías radicales anglosajona e hispana. Rev. do Museu de Arqueologia e Etnologia, São Paulo, Suplemento 3: 181-199, 1999.

meramente arqueológicos, y la necesidad de incorporar estos desarrollos específicos dentro de discusiones de carácter más general pertinentes a los problemas de la sociedad actual.

En el caso latinoamericano podemos citar la experiencia del Museo del Hombre Venezolano, entre 1984 y 1987 (Vargas 1992). Este proyecto fue desarrollado por Mario Sanoja e Iraida Vargas dentro de la Universidad Central de Venezuela en Caracas, uno de los principales centros académicos de Venezuela y a su vez uno de los más aguerridos centros de desarrollo de teorías y acciones políticas de oposición o alternativas. La misión del Museo, especialmente dirigido a un público infantil o juvenil, era la de ofrecer una lectura alternativa de la historia nacional enfatizando más en los procesos que en los eventos, más en los grupos sociales que los personajes, más en las contradicciones y luchas - internas y externas - que en la tendencia al progreso acumulativo y ascendente, más en la construcción de una identidad nacional que en el recuento anecdótico. Con este fin, la primera - y única - exhibición, denominada "Tres Culturas, Una Nación" pretendía enfrentarse a la visión oficial de la historia venezolana desde varios flancos.

En primer lugar, a partir de una visión retrospectiva desde el presente en los ochentas hasta los primeros pobladores de continente americano, el museo suponía romper con los cajones estancos que la periodificación de la historia oficial impone y así enfatizar en la continuidad. Por otro lado, la predominante incorporación de la historia indígena prehispánica en el guión museográfico no sólo enfatizaba la enorme importancia de esta cultura sino también su prolongada permanencia en la historia nacional. Igualmente, la incorporación de temas relacionados con las comunidades negras, indígenas y las clases obreras venezolanas representó un evidente desafío a la visión elitista y europocéntrica propuesta por la historia hegemónica. En términos museográficos, la exhibición enfatizó en el contenido más que la exhibición de objetos, lo cual evidentemente representó una alternativa frente a los tradicionales museos de historia. Igualmente, en vez de ofrecer una lectura individual de la exhibición debía de visitado bajo guiaturas, las cuales conducían y propiciaban la apreciación y la capacidad crítica del visitante, lo cual también se relacionaba con una visión programática y política de la acción cultural.

Sin embargo, el Museo fracasó. Las razones de su desaparición son complejas y múltiples y van desde procesos nacionales hasta la praxis de los agentes sociales como individuos. Una de las principales razones fue el escaso interés de la opinión pública en general en relación con las actividades del museo. En un país como Venezuela, en donde no existe un Museo de Historia Nacional, este desinterés es parte de la ideología imperante. Sin embargo, la ubicación de la exhibición dentro la Universidad Central de Venezuela también representó un obstáculo para su incorporación en el circuito cultural nacional ya que la circulación del público - al menos que asistieron de manera voluntaria se concretó en los sectores de la población conectados con el ámbito universitario: la clase media profesional. En este sentido, el Museo no se conectó con las clases populares, las cuales eran su receptor potencial, con la excepción de las escuelas públicas que asistieron a las guiaturas.

Mas aún, aún cuando el enfrentamiento a la historia hegemónica era explícito algunas de las nociones que subyacían al discurso propuesto por la exhibición "Tres Culturas, Una Nación", desde su propio título, tendían peligrosamente a reforzar postulados básicos del Estado Nacional. La idea de mestizaje, la cual está implícita en la celebración del Día de la Raza el 12 de Octubre, ha sido uno de los principales instrumentos de control y apropiación histórica que las élites criollas latinoamericanas han utilizado para absorber o diluir el potencial político de los sectores marginalizados racialmente (Badillo 1995, Sorensen 1997). Aunque la exhibición insistía en una lectura crítica de estas nociones, en cierto modo continuaba funcionando sobre la misma visión de igualdad racial y cultural - al menos como projecto político para alcanzar la justicia social. Al fin al cabo, era una propuesta de las clases medias intelectuales, convertidas en vanguardia académica, para una masa que al fin terminaba siendo la misma clase media profesional.

Esta experiencia en Latinoamérica tiene su paralelo también en el caso de los EE.UU. y, paradójicamente, sus problemas y limitaciones reflejan problemáticas bastantes similares. Annapolis (Maryland, EE.UU.) es una pequeña ciudad cercana a Washington D.C., fundada en 1650 y que durante la segunda, mitad del siglo XVIII representó un importantísimo centro de desarrollo sociopolítico y cultural en el contexto estadounidense, siendo la capital del Estado de Maryland desde 1695 hasta principios del siglo XIX. Estas cirscuns- 
McGUIRE, R.H.; NAVARRETE, R. Entre motocicletas y fusiles: las arqueologías radicales anglosajona e hispana. Rev. do Museu de Arqueologia e Etnologia, São Paulo, Suplemento 3: 181-199, 1999.

tancias la han convertido en foco turístico y de recreación histórica adonde gran cantidad de la población de los EE.UU. asiste a "aprehender y disfrutar" su historia nacional. Aprovechando el auge en los proyectos de restauración histórica y en el énfasis histórico de este contexto urbano, en 1981 un proyecto de excavación e interpretación arqueológica histórica fue especialmente diseñado para atacar las nociones tradicionales del período colonial norteamericano focalizándose en las contradicciones y desigualdades sociales que lo caracterizaron (Leone, Potter y Schackel 1987, Leone 1995). Sus promotores, Richard Dent, Mark Leone y Anne Yentsh aspiraban, a partir de una experiencia participativa, que el público obtuviera una lectura crítica del pasado colonial de los EE.UU.

A partir de una investigación etnográfica el equipo de investigación había determinado que el público que asistía a Annapolis obtenía una visión fragmentaria de la historia de la ciudad la cual reflejaba la ideologización de la historia nacional. A partir de una total separación de las diversas continuidades espaciales e históricas de la ciudad, tales como siglo XVIII - siglo XIX o blancos - negros, se reforzaba no sólo la visión estática y armónica del pasado nacional sino también se escondían las contradicciones del pasado y se justificaban las desigualdades del presente. Para enfrentar esta ideologización del pasado - entendida ideología en el sentido althusseriano de falsa conciencia (Althusser 1969) - el proyecto ofrecía una visita guiada del casco histórico de la ciudad y de las excavaciones arqueológicas de Annapolis en la que se explicaba a la audencia como los restos materiales y la arquitectura urbana de la ciudad expresaban y reforzaban las desigualdades sociales de la época. Se hacía un fuerte énfasis en como la industrialización produjo una masificación de bienes y también generó la división entre aquéllos que podían entrar en el circuito comercial y adquirir los bienes y quienes eran marginalizados según su poder adquisitivo. Igualmente se enfatizaba que las reglas de segmentación y separación establecidas en la vida cotidiana estadounidense desde el siglo XVIII, y expresadas en todos los aspectos materiales de la vida diaria (vajillas, cubiertería, espacios domésticos y públicos, etc.) no sólo se originaron de la definición de una nueva estructura clasista sino que legitimaban la desigualdad racial y de clases día a día a través de las conductas sociales habituales.

Sin embargo, el proyecto político de concientización histórica y de desenmascaramiento de las ideologías históricas sucumbió frente a las limitaciones que la historia oficial y el propio circuito cultural le impuso (Leone 1995). En primer lugar, aún cuando se intentaba generar una respuesta crítica frente a la historia, el público generalmente adecuó el discurso de las guiaturas a sus preconcepciones. Mientras los arqueólogos estaban preocupados por demostrar la desigualdad en el pasado y su relación con la discriminación racial y la lucha de clases en el presente, el público mas bien se interesó en los aspectos exóticos de ese pasado. Lo exótico, lo monumental, lo extraordiario fueron el foco de la respuesta del publico, conjuntamente con preocupaciones típicas de la ideología capitalista actual, tales como el precio o valor de los objetos, el tiempo invertido en producirlo, la disponibilidad en el mercado, etc.

Sin embargo, esta respuesta no es azarosa y está claramente relacionada con el perfil del público captado y con las necesidades históricas de la comunidad. En general, aquellos que asistían voluntariamente y que estaban interesados en la historia nacional eran precisamente aquellos que habían surgido de los sectores privilegiados de la sociedad, la clase media anglosajona profesional. Una vez más, las relaciones de poder estaban incidiendo en la circulación y adquisición del conocimiento en la sociedad. Más importante aún, según Leone siguiendo a Luckás (1971), este fenómeno reflejaba claramente la distorsión y reificación histórica en las masas producida por la ideología hegemónica. Las desigualdades y la explotación eran naturalizadas y universalizadas por el público al reflejar la visión del pasado armónico en el caso de Annapolis.

En consecuencia, Leone (1995), esta vez siguiendo las nociones de acción comunicativa de Habermas (1984), posteriormente recondujo su propuesta hacia aquellos sectores de la sociedad que se sintieran más directamente afectados por las contradicciones coloniales. Es así como enfatizó el problema de la esclavitud y se concentró en conducir su propuesta hacia las comunidades afroamericanas incorporándolas activamente en la relaboración y comprensión del programa. Sin embargo, aún así la distancia entre el arqueólogo como vanguardia intelectual que pretende "concientizar" a las masas y las preocupaciones y necesidades de la propia comunidad fue difícil de flanquear. Al margen de que un proyecto como éste propone un discurso histórico alternativo, las propias comunidades ya han asimilado el discurso hegemónico y, 
más aún, se han apropiado de símbolos y representaciones históricas que son utilizadas para su propio provecho político.

Es así como el salto de la teoría a la praxis es uno de los procesos más conflictivos y difíciles de resolver para una arqueología comprometida. Las propias contradicciones del discurso arqueológicos y los agentes sociales que lo producen, más aquellas relacionadas con el contexto social en que se produce y distribuye el conocimiento se entretejen de manera compleja (Yoffe y Sharrett 1993, Kohl y Fawcett 1995). Precisamente para entender y actuar en esta praxis dialéctica consideramos que la arqueología debe ser entendida como un oficio artesanal (Shanks y McGuire 1996). Con esta idea estamos proponiendo que la labor del arqueólogo no debe ser entendida como una búsqueda de conocimientos absolutos, abstractos y elevados por una élite científica que dictamina según criterios de objetividad, sino más como un contante y cambiante proceso productivo que implica la aplicación de destrezas, el conocimiento de la materia prima y el contacto directo con ella. Requiere también de una constante reevaluación del producto último y de su vinculación funcional con un público o sociedad que lo demanda como necesidad social. Más aún, esta visión permite disolver la dicotomía postrenacentista entre ciencias y humanidades, artes y oficios, bellas artes y artesanía, belleza y función, deleite e intención, proponiendo la unificación del sentido intelectual y práctico de las acciones humanas. Incluso, reenlazando estos procesos, supone la unificación entre razón y sensibilidad, conocimiento y acción, ciencia y política. Sólo así, en una constante interacción crítica entre conocimiento, crítica y acción, podemos realmente, al igual que el Ché Guevara, llevar a cabo una verdadera praxis revolucionaria a partir de la arqueología.

Esta reevaluación permanente del conocimiento producido en interacción con el contexto social impone la necesidad de una posición crítica frente a la historia como proceso y como conocimiento. Es necesario entonces reevaluar en primer lugar la audiencia a la cual estamos dirigiéndonos así como los mecanismos y medios comunicativos que estamos utilizando. Si somos capaces de tomar conciencia de que la audiencia de los medios de educación y divulgación - formales e informales - que estamos utilizando está históricamente representada por los sectores intelectuales y la clase media, sería necesario entonces repensar nuestras estrategias de difusión y participación. Es necesario entonces no sólo definir nuestra perspectiva sino también la audiencia potencial a la que queremos dirigirnos y, sobre todo, reflexionar sobre las consecuencias políticas de la difusión del conocimiento histórico en nuestra sociedad. Como en el caso de la experiencia de Leone en Annapolis, consideramos que es necesario evaluar el potencial crítico o revolucionario de los diversos sectores sociales y apuntar hacia aquéllos que puedan responder con una praxis congruente frente a nuestros planteamientos.

Igualmente, los medios seleccionados para la difusión deben ser evaluados bajo los parámetros culturales y socioeconómicos de la audiencia potencial. Los museos y universidades pueden ser medios ideales para algunos acercamientos pero su condicionamiento obliga a pensar sus rígidas estructuras. Un medio que se ha popularizado recientemente, y publicitado como la definitiva utópica democratización y deconstrucción de los mecanismos hegemónicos de la información, es el ciberespacio (Lyotard 1984, Poster 1990). Sin embargo, frente a este medio debemos ser más cautos porque sus implicaciones clasistas e imperialistas en relación al acceso y control de la información parecen más bien apuntar hacia un contexto conservador - probablemente por esto ha sido exaltado con tanta euforia y vehemencia por los discursos postmodernos. En definitiva, los medios de comunicación y difusión deben ser accesibles, comprensibles y relevantes para los sectores sociales a los que nos queremos dirigir.

Igualmente, una evaluación autocrítica de nuestra posición como científicos sociales o intelectuales nos lleva a pensar en nuestro posicionamiento en la sociedad. Está claro que el arqueólogo representa a un sector social privilegiado. En primer lugar, está asociado a una disciplina científica y académica que ha reforzado históricamente el colonialismo y la dominación a través de una visión de la historia enajenante y cosificante. En segundo lugar, el saber arqueológico representa una visión de la historia enraizada en nociones europocéntricas pero que intenta apropiarse, bajo una visión globalizante, de las historias de otras tradiciones culturales o sociales. Tercero, el arqueólogo como sujeto social está directamente asociado a los sectores medios profesionales de la sociedad y como tal no puede escapar a las preconcepciones 
McGUIRE, R.H.; NAVARRETE, R. Entre motocicletas y fusiles: las arqueologías radicales anglosajona e hispana. Rev. do Museu de Arqueologia e Etnologia, São Paulo, Suplemento 3: 181-199, 1999.

ideológicas que su condición de clase le impone. Cuarto, la arqueología como disciplina ha formado frecuentemente parte de la ideología de Estado ya que se relaciona con el rescate - o la construcción - de un pasado nacional y por lo tanto mantiene un inevitable vínculo institucional e ideológico con los mecanismos de control estatal. Quinto y último, la posición política del arqueólogo es ambigua ya que mientras propone una lectura critica del pasado está a su vez imponiéndola desde la elitesca posición de la vanguardia intelectual, frecuentemente desvinculada de las necesidades de los sectores oprimidos.

Es así como, sin una visión crítica de nuestra praxis, podemos facilmente formar parte de la opresión. Un caso típico es el proceso de repatriación y reentierro que las comunidades indígenas han estado promoviendo en los EE.UU. en la última década. A lo largo de todas las Américas los arqueólogos han construido sus carreras estudiando la herencia de los indígenas americanos. En consecuencia, la arqueología americana ha representado en gran medida una empresa colonialista, es decir, el estudio de la historia de los vencidos en la conquista. Este es claramente el caso de los Estados Unidos de América. Mientras las fuerzas armadas estadounidenses empujaban a las naciones indígenas hacia el Oeste y dentro de reservaciones, los antropólogos y arqueólogos reclamaban sus derechos sobre el pasado indígena americano (McGuire 1992).

A fines del siglo XIX los antropólogos incluso profanaron enterramientos indígenas en busca de restos humanos frescos, los que también colectaron en campos de batalla. Es precisamente desde esta posición que los antropólogos y arqueólogos escribieron la historia de la América indígena. Los indígenas americanos actuales, especialmente en Norteamérica, han visto las excavaciones arqueológicas del siglo XX simplemente como la continuación de estas macabras prácticas. De hecho en sus posiciones más radicales han afirmado que los arqueólogos debían ser arrestados por excavar tumbas en vez de ser recompensados con posiciones académicas en los museos y universidades.

Por esta razón cuando los indígenas norteamericanos hicieron de la arquelogía un espacio de lucha señalaron inmediatamente la opresión política escondida tras la arqueología estadounidense
(Deloria 1973, 1995; Antone 1986). La lucha por la repatriación requería un compromiso real con la acción política y conllevaba un alto grado de riesgo que estaba en gran medida ausente en las discusiones abstractas y los discursos hegemónicos. El puñado de arqueólogos estadounidenses que apoyaron la posición de los indígenas americanos y presionaron por una reforma de la arqueología fueron vistos como traidores y denigrados por muchos colegas en su campo. A muchos de ellos les fueron rechazados solicitudes de trabajo, negadas sus oportunidades de publicaciones, sus presentaciones en encuentros nacionales fueron relegadas y se les negaron ascensos debido a ser considerados "muy políticos" (Zimmerman 1992).

Afortunadamente, la realidad sociopolítica no es tan mecánica y estructurada como hasta ahora el pensamiento positivista moderno la había representado y sus ambiguedades y contradicciones nos ofrecen espacios para mobilizar activamente nuestra resistencia a las condiciones impuestas.

Rebeldía o rebelión. Reformismo o revolución. James Dean o el Ché. Aún cuando en estos momentos de fin de siglo estos íconos parezcan caducos, a su vez parecieran mantener vigencia en las alternativas políticas asumidas por diversos sectores de la sociedad, incluyendo a la comunidad intelectual y por lo tanto la arqueológica. Al menos así creemos que se manifiesta en la diferenciación entre los contextos arqueológicos radicales anglófono y hispanoparlante. De manera congruente, el James Dean individualista y reformista ha caracterizado en gran medida a las propuestas radicales en los contextos norteamericanos e ingleses, mientras que los programas colectivos altamente politizados y socialmente comprometidos definen la Arqueología Social Latinoamericana. Sin embargo, no quisieramos finalizar con la idea de que cada tradición histórico cultural está atrapada dentro de los patrones de los modelos contrapuestos. Es que acaso no puede haber una visión revolucionaria en el contexto ąnglófono? No son acaso también comunes las propuestas reformistas en el contexto latinoamericano? Consideramos que únicamente con una visión críticà del contexto socio-científico y de la relación entre teoría y práctica es posible entender las arqueologías radicales y su vinculación con las necesidades sociales. 
McGUIRE, R.H.; NAVARRETE, R. Entre motocicletas y fusiles: las arqueologías radicales anglosajona e hispana. Rev. do Museu de Arqueologia e Etnologia, São Paulo, Suplemento 3: 181-199, 1999.

\section{Bibliografia}

ALTHUSSER, L.

1969 For Marx. New York: Vintage.

ANTON, C.F.

1986 Reburial: A Native American Point of View. World Archaeological Congress, Southampton.

BADILLO, J.S.

1995 The Theme of the Indigenous in the National Projects of the Hispanic Caribbean. P.R. Schmidt; T.C. Patterson (Eds.) Making Alternative Histories: The Practice of Archaeology and History in Non-Western Society. Santa Fe, School of American Research.

BAPTY, I.; YATES, T. (Eds.)

1990 Archaeology after Structuralism. London: Routledge.

\section{BATE, L.F.}

1977 Arqueología y Materialismo Histórico. México: Ediciones de Cultura Popular.

1981 Relación General entre Teoría y Método en Arqueología. Boletín de Antropología Americana. México, 4.

1982 Hacia la Cuantificación de las Fuerzas Productivas en Arqueología. Boletín de Antropología Americana. México, 6.

1983 Comunidades Primitivas de Cazadores y Recolectores en Suramérica. Historia General de América, N. 1, Caracas, Ediciones de la Presidencia de la República. Hipótesis sobre la Sociedad Clasista Inicial. Boletín de Antropología Americana, México, 9.

1986 El Modo de Producción Cazador Recolector o la Economía del Salvajismo. Boletín de Antropología Americana, México, 13.

1989 Notas sobre el Materialismo Histórico en el Proceso de Investigación Arqueológica. Boletín de Antropología Americana. México, 19.

1992 Las Sociedades Cazadoras Recolectoras Pretribales o el "Paleolítico Superior" Visto desde Suramérica. Boletín de Antropología Americana, México, 25.

1992 Del Registro Estático al Pasado Dinámico: Entre un Salto Mortal y un Milagro Dialéctico". Boletín de Antropología Americana. México, 26.

1993 Teoría de la Cultura y Arqueología. Boletín de Antropología Americana, México, 27.

\section{BENDER, $\mathrm{B}$.}

1989 The Roots of Inequality. D. Miller; M. Rowlands; C. Tilley (Eds.) Domination and Resistance. London, Unwin and Hyman: 83-95.

1990 The Dynamics of Nonhierarchical Societies. S. Upham (Ed.) The Evolution of Political Systems: Socio-Politics in Small Scale Sedentary Societies. Cambridge, Cambridge University Press: 247-263.

1998 Stonehenge: Making Space. Oxford: Berg.

BERNAL, I.

1979 Historia de la Arqueología en México. México D.F.: Editorial Porrúa.
CASO, A.

1958 Indigenismo. México D. F., Instituto Nacional de Indigenismo (INI).

CHIPPINDALE, $\mathrm{C}$.

1993 Ambition, deference, discrepancy, consumption: the intellectual background to a post-processual archaeology. N. Yofee; A. Sherrat (Eds.) Archaeological Theory. Who Sets the Agenda? Cambridge: Cambridge University Press.

CLAASSEN, C.; JOYCE, R. (Eds.)

1997 Women in Prehistory. North America and Mesoamerica. Philadelphia: Pennsylvania University Press.

CORONIL, F.

1997 The Magical State. Nature, Money, and Modernity in Venezuela. Chicago: The University of Chicago Press.

DAVIES, D.D

1996 Revolutionary Archaeology in Cuba. Journal of Archaeological Method and Theory, 3 (3).

DELORIA, V., Jr.

1973 God is Red. New York: Grosset and Dunlap.

1995 Red Earth, White Lies: Native Americans and the Myth of Scientific Facts. New York: Simon and Schuster.

FERNANDEZ LEIVA, $O$.

1992 Desarrollo del Pensamiento Arqueológico en Cuba. G. Politis (Comp.) Arqueología en América Latina Hoy. Bogotá, Colombia: Fondo de Promoción de la Cultura del Banco Popular.

GANDARA, $M$.

1980 La Vieja Nueva Arqueología. Primera Parte. Boletín de Antropología Americana, México, 2.

1981 La Vieja Nueva Arqueología. Segunda Parte. Boletín de Antropología Americana. México, 3.

1985 Arqueología y Marxismo en México. Boletín de Antropología Americana, México, 11.

1987 Hacia una Teoría de la Observación en Arqueología. Boletín de Antropología Americana. México, 15.

1988 Observaciones sobre el Término Teórico 'Estado Arcaico' L. Manzanilla (Comp.) Coloquio V. Gordon Childe. Estudios sobre las Revoluciones Neolítica y Urbana. México D. F.: Universidad Nacional Autónoma de México.

1990 Algunas Notas sobre el Análisis del Conocimiento. Boletín de Antropología Americana, México, 22.

1992 El Análisis Teórico: Aplicaciones al Estudio del Origen de la Complejidad Social. Boletín de Antropología Americana. México, 25.

1992 La Arqueología Oficial Mexicana. Causas y Efectos. Mexico D.F.: Instituto Nacional de Antropología e Historia.

1993 El Análisis de Posiciones Teóricas: Aplicaciones a la Arqueología Social. Boletín de Antropología Americana, México, 27. 
McGUIRE, R.H.; NAVARRETE, R. Entre motocicletas y fusiles: las arqueologías radicales anglosajona e hispana. Rev. do Museu de Arqueologia e Etnologia, São Paulo, Suplemento 3: 181-199, 1999.

GASSON, R.; WAGNER, E.

1994 Venezuela: Doctors, Dictators and Dependency (1932 to 1948). A. Oyuela-Caycedo (Ed.) History of Latin American Archaeology. Glasgow: Avebury.

GERO, J.M.; CONKEY, M.W. (Eds.)

1991 Engendering Archaeology: Women and Prehistory. Oxford UK: Basil Blackwell.

GILMAN, A.

1984 Explaining the Upper Paleolithic Revolution. M. Spriggs (Ed.) Marxist Perspectives in Archaeology. Cambridge: Cambridge University Press.

GRAMSCI, A.

1971 Selections from the Prison Notebooks. New York: International Publishers.

GUARCH, J.M.

1987 Arqueología de Cuba. Métodos y Sistemas. La Habana: Editorial de Ciencias Sociales.

GUEVARA, E.

1994 Mi Primer Gran Viaje: De la Argentina a Venezuela en motocicleta. Buenos Aires: Seix Barral.

1995 The Motorcycle Diaries: A Journey Around South America. London and New York: Verso.

HABERMAS, J.

1984 The Theory of Communicative Action. Boston: Beacon Press.

HANDSMAN, R.G.

1983 Historical Archaeology and Capitalism, Subscriptions and Separations: The Production of Individualism. North American Archaeologist, 4 (1): 63-79.

HARNECKER, $M$

1969 Los Conceptos Elementales del Materialismo Histórico. México: Siglo Veintiuno.

HODDER, I. (Ed.)

1982 Symbolic and Structural Archaeology. Cambridge: Cambridge University Press.

1986 Reading the Past: Current Approaches to Interpretation in Archaeology. Cambridge, Cambridge University Press.

HODDER, I. et al.

1995 Interpreting Archaeology: Finding Meaning in the Past. London: Routledge.

KOHL, P.L

1981 Materialist Approaches to Prehistory. Annual Review of Anthropology, 10: 89-118.

1985 Symbolic, Cognitive Archaeology: A New Loss of Innocence. Dialectical Anthropology, 9: 105-117.

1989 The Use and Abuse of World Systems Theory: the Case of the "Pristine" West Asian State. C.C. Lamberg-Karlovsky (Ed.) Archaeological Thought in America. Cambridge: Cambridge University Press.

KOHL, P.L.; FAWCETT, C. (Eds.)

1995 Nationalism, Politics, and the Practice of Archaeology. Cambridge: Cambridge University Press.
LEONE, M.P.

1981 The relationship between artifacts and the public in outdoor history museums. A. Cantwell; N. Rothschild; J. Griffen (Eds.) The Research Potential of Anthropological Museum Collections. New York: New York Academy of Sciencies.

1982 Some Opinions About Recovering Mind. American Antiquity, 47: 742-760.

1988 The Georgian Order as the Order of Merchant Capitalism in Annapolis, Maryland. M.P Leone; P.B. Potter Jr. (Eds.) The Recovery of Meaning: Historical Archaeology in the Eastern United States. Washington D.C., Smithsonian Institution Press: 263-292.

1995 A Historical Archaeology of Capitalism. American Anthropologist, 97 (2): 251-268.

LEONE, M.P.; POTTER, P.B.; SHACKEL, P.A.

1987 Toward a Critical Archaeology. Current Anthropology, 28 (3): 283-302.

LUKACS, G.

1971 Reification and the consciousness of the proletariat. R. Livingstone (Ed.) History and Class Conciousness. Cambridge MA: MIT Press.

LORENZO, J.L. et al.

1976 Hacia una Arqueología Social: Reunión de Teotihuacán. México D.F.: INAH.

LORENZO, J.L.

1991 Prehistoria y Arqueología. México D.F.: INAH e Historia.

LUMBRERAS, L.G.

1974 La Arqueología como Ciencia Social. Lima: Ediciones Histar.

1981 Organización y Economía Inka. W. Espinoza Soriano (Ed.) Los Modos de Producción en el Imperio de los Incas. Lima, Perú: Amaru Editores.

1983 Las Sociedades Nucleares de América. Historia General de América, N. 4. Caracas: Ediciones de la Presidencia de la República.

1986 Una Nueva Visión del Antiguo Perú. Lima, Perú: Municipalidad de Lima Metropolitana.

1988 De los Orígenes de la Civilización en el Perú. Lima, Perú: Peisa.

1988 Childe y la Tesis de la Revolución Urbana: La Experiencia Central Andina. L. Manzanilla (Comp.) Coloquio V. Gordon Childe. Estudios sobre las Revoluciones Neolitica y Urbana. México D. F.: Universidad Nacional Autónoma de México.

1989 Chavín de Huantar. Lima: Indea.

1990 Visión Arqueológica del Perú Milenario. Lima, Perú: Editorial Milla Batres.

LYOTARD, J.F

1984 The Postmodern Condition: A Report on Knowledge. Minneapolis: University of Minnesota Press.

MARIATEGUI, J.C.

1973 Siete Ensayos de Interpretación de la Realidad Peruana. Barcelona, España: Editorial Crítica. 
McGUIRE, R.H.; NAVARRETE, R. Entre motocicletas y fusiles: las arqueologías radicales anglosajona e hispana. Rev. do Museu de Arqueologia e Etnologia, São Paulo, Suplemento 3: 181-199, 1999.

MATOS MENDIETA, $R$.

1994 Peru: Some Comments. A. Oyuela-Caycedo (Ed.) History of Latin American Archaeology. Glasgow: Avebury.

McGUIRE, R.H.

1992 A Marxist Archaeology. San Diego: Academic Press.

MONTANE, J.

1980 Marxismo y Arqueología. México: Ediciones de Cultura Popular.

NAVARRETE, $R$.

1995 Antiguos Caminos y Nuevos Senderos: Existe una Arqueología Postmoderna en Venezuela?. Cuadernos de Postgrado, Caracas, Venezuela, Fondo Editorial Tropykos-Universidad Central de Venezuela, 10.

1998 Latin American Social Archaeology: One Goal, Multiple Views. Tesis de Maestría, SUNY Binghamton University.

OCHOA, L. et al.

1989 Reflexiones en torno a la Arqueología Mexicana. L. Mirambell (Comp.) Homenaje a José Luis Lorenzo. México: Instituto Nacional de Antropología e Historia.

OYUELA-CAYCEDO, A.

1994 Nationalism and Archaeology: A Theoretical Perspective. A. Oyuela-Caycedo (Ed.) History of Latin American Archaeology. Glasgow: Avebury.

OYUELA-CAYCEDO, A. et al.

1997 Social Archaeology in Latin America?: Comments to T. C. Patterson. American Antiquity, 62 (2).

\section{PATTERSON, T.C.}

1986 The last sixty years: towards a social history of Americanist archaeology in the United States. American Anthropologist, 88 (1): 7-26.

1994 Social Archaeology in Latin America: An Appreciation. American Antiquity, 59 (3): 531-537.

1995 Archaeology, History, Indigenismo and the State in Peru And Mexico. P.T. Schmidt; T. Patterson (Eds.) Making Alternatives Histories: The Practices of Archaeology and History in Non-Western Societies. Santa Fe: School of American Research Press.

1997 A Reply to A. Oyuela-Caycedo, A. Anaya, C.G. Elera, and L.M. Valdez. American Antiquity, 62 (2).

PAYNTER, $\mathbf{R}$

1989 The Archaeology of Inequality. Annual Review of Anthropology, 18: 369-99.

PREUCEL, R. (Ed.)

1991 Processual and Post-Processual Archaeologies: Multiple Ways of Knowing the Past. Carbondale, Ill: University of Southern Illinois.

POLITIS, G.

1995 The Socio-Politics of the Development of Archaeology in Hispanic South América. P.Ucko (Ed.) Theory in Archaeology: A World Perspective. London, Routledge.

POSTER, M.

1990 The Mode of Information. Chicago: University of Chicago Press.
ROWLANDS, $\mathrm{M}$.

1989 A Question of Complexity. D. Miller; M. Rowlands; C. Tilley (Eds.) Domination and Resistance. Hyman Unwin, London: 29-40.

SAITTA, D.

1988 Marxism, Prehistory, and Primitive Communism. Rethinking Marxism, 1 (4):146-168.

1989 Dialectics, Critical Inquiry, and Archaeology. A. Wylie; V. Pinsky (Eds.) Critical Traditions in Contemporary Archaeology. Cambridge, Cambridge University Press: 38-43.

1997 Power, Labor, and the Dynamics of Change in the Chacoan Political Economy. American Antiquity, 62 :7-26.

SANOJA, M.

1979 Las Culturas Formativas del Oriente de Venezuela. La Tradición Barrancas del Bajo Orinoco. Caracas: Biblioteca de la Academia Nacional de la Historia.

1981 Los Hombres de la Yuca y el Maíz. Un Ensayo sobre el Orígen y Desarrollo de los Sistemas Agrarios en el Nuevo Mundo. Caracas: Monte Avila Editores.

19837 Temas de Debate en la Arqueología Social. Cuadernos de Antropología No. 2, San José, Universidad de Costa Rica.

1983 De la Recolección a la Agricultura. Historia General de América, N. 3, Caracas: Ediciones de la Presidencia de la República.

1984 La Inferencia en Arqueología Social. O. Fonseca (Ed.) Actas del Primer Simposio de la Fundación de Arqueología del Caribe. Hacia una Arqueología Social. Washington D.C.: Latin American Foundation.

1987 Historia Ilustrada de Venezuela. Período Indigena. Tomo I, Caracas: Ediciones Mediciencia.

1989 Los Orígenes del Cultivo en el Noroeste de Venezuela. L. Mirambell (Comp.) Homenaje a José Luis Lorenzo. México: Instituto Nacional de Antropología e Historia.

1990 The Venezuelan Colonial Way of Life. Revista de Arqueología Americana, México: Instituto Panamericano de Geografía e Historia, 2.

1991 La Huella Asiática en el Poblamiento de Venezuela. Caracas: Cuadernos Lagoven.

1994 Gente de la Canoa: Ensayo sobre los Antiguos Modos de Vida Recolectores del Noreste de Venezuela. Caracas: Fondo Editorial Trópikos.

SANOJA, M.; VARGAS, I.

1992 Antiguas Formaciones y Modos de Producción Venezolanos. Caracas: Monte Avila Editores.

SHANKS, M.; TILLEY, C.

1987a Re-Constructing Archaeology. Cambridge: Cambridge University Press.

1987b Social Theory and Archaeology. Cambridge: Cambridge University Press.

SHANKS, M.; McGUIRE, $R$.

1996 The Craft of Archaeology. American Antiquity, 61 (1):75-88. 
McGUIRE, R.H.; NAVARRETE, R. Entre motocicletas y fusiles: las arqueologías radicales anglosajona e hispana. Rev. do Museu de Arqueologia e Etnologia, São Paulo, Suplemento 3: 181-199, 1999.

SORENSEN, N.N.

1995 There no Indians in the Dominican Republic: The cultural construction of Dominican identities. K.F. Olwig; K. Harstrup (Eds.) Siting Culture. New York and London: Routledge.

TABIO, E.; REY, E.

1985 Prehistoria de Cuba. La Habana: Editorial de Ciencias Sociales.

TILLEY, C. (Ed.)

1990 Reading Material Culture: Structuralism, Hermeneutics and Post-structuralism. Oxford: Basil Blackwell.

1993 Interpretative Archaeology. London: Berg.

TRIGGER, B.G.

1978 Time and Traditions: Essays in Archaeological Interpretation. New York: Columbia University Press

1984 Alternative archaeologies: nationalist, colonialist, imperialist. Man, 19: 355-370.

1989a A History of Archaeological Thought. Cambridge: Cambridge University Press.

1989b Hyperrelativism, responsibility and the social sciences. Canadian Review of Sociology and Anthropology, 26: 776-97.

VALCARCEL, L.E.

1978 Historia del Perú Antiguo. Vol. I y II. Lima, Perú: Editorial Juan Mejía Baca.

1981 El Estado Inca. W. Espinoza Soriano (Ed.) Los Modos de Producción en el Imperio de los Incas. Lima, Perú, Amaru Editores.

VARGAS, I.

1976 Introducción al Estudio de las Ideas Antropológicas en Venezuela: 1880-1936. Semestre Histórico, Caracas, 3.

1979 La Tradición Saladoide del Oriente de Venezuela. La Fase Cuartel. Caracas: Biblioteca de la Academia Nacional de la Historia.

1981 Investigaciones Arqueológicas en Parmana. Los Sitios de La Gruta y Ronquin. Caracas: Biblioteca de la Academia Nacional de la Historia.

1984 Definición de Conceptos para una Arqueología Social. O. Fonseca (Ed.) Actas del Primer Simposio de la Fundación de Arqueología del Caribe. Hacia una Arqueología Social. Washington D.C., Latin American Foundation.
1986 Evolución Histórica de la Arqueología en Venezuela. Quiboreña,Quíbor, Venezuela, Museo Arqueológico de Quíbor, 1.

1990 Arqueología, Ciencia y Sociedad. Ensayo sobre Teoría Arqueológica y la Formación Económico Social Tribal en Venezuela. Caracas: Editorial Abrebrecha.

1995 The Perception of History and Archaeology in Latin America. P.T. Schmidt; T. Patterson (Eds.) Making Alternatives Histories: The Practices of Archaeology and History in NonWestern Societies. Santa Fe, School of American Research Press.

VARGAS, I.; et al.

1984 Los Artífices de la Concha. Caracas: Biblioteca de la Academia Nacional de la Historia.

VARGAS, I.; SANOJA, $M$.

1993 Historia, Identidad y Poder. Caracas: Fondo Editorial Tropykos.

VASQUEZ LEON, L.

1994 Mexico: The Institutionalization of Archaeology, 1885-1942. A. Oyuela-Caycedo (Ed.) History of Latin American Archaeology. Glasgow. Avebury.

WALL, D.

1994 The Archaeology of Gender: Separating the Spheres in Urban America. New York: Plenum Press.

WRIGHT, R.

1996 Gender and Archaeology. Philadelphia: University of Pennsyilvania Press.

WURST, L.A.

1991 Employees Must Be of Moral and Temperate Habits, Rural and Urban Elite Ideologies. R.H. McGuire; R. Paynter (Eds.) The Archaeology of Inequality. Oxford, Basil Blackwell: 125150.

WYLIE, A.

1992 The interplay of Evidential Constraints and Political Interests: Recent Archaeological Research on Gender. American Antiquity, 57: 15-35.

YOFEE, N.; SHERRAT, $S$.

1993 Archaeological Theory: Who Sets the Agen$d a$ ? Cambridge: Cambridge University Press. 